Revista de DeRecho UNED, NÚM. 11, 2012

\title{
LA CODIFICACIÓN EN ESPAÑA DURANTE LA DECADA MODERADA Y EL BIENIO PROGRESISTA
}

\author{
CODIFICATION IN SPAIN DURING THE DÉCADA MODERADA \\ (MODERATE DECADE) AND THE BIENIO PROGRESISTA \\ (PROGRESSIVE BIENNIUM)»
}

Dolores del MAR SÁNCHEZ GonZÁLEZ

Profesora Titular de Historia del Derecho

Universidad Nacional de Educación a Distancia (UNED)

Resumen: La codificación española se ha abordado siempre con carácter parcial agrupando cada una de las grandes áreas temáticas del Derecho y analizando las peculiaridades de la codificación en cada una de esas áreas. Pero no existe una historia institucional de las diferentes Comisiones de Códigos, previas a la Comisión General de Codificación, vinculadas en mayor o menor medida al Ministerio de Justicia. Este trabajo, que es continuación de otros dos anteriores, trata de reconstruir la codificación a nivel institucional en cuanto a órganos del Ministerio, a través de su funcionamiento y de las personas que participaron en las mismas a fin de poder elaborar teorías ideológico acerca de sus actuaciones y toma de decisiones, centrándose en dos periodos del reinado isabelino: la década moderada y el bienio progresista.

Palabras clave: codificación, comisiones de códigos, siglo XIX, Isabel II de España.

Abstract: The Spanish codification has been approached always by partial character grouping each of the big thematic areas of the Law, and analyzing the peculiarities of the codification in each of these areas. But there does not exist an institutional history of the different Commissions of Codes, before the General Commission of 
Codification, linked in major or minor measure to the Department of Justice. This work, which is a continuation of other two previous ones, tries to reconstruct the codification to institutional level as for organs of the Department, across his functioning and of the persons who took part in the same ones in order to be able to elaborate theories ideologically it brings over of his actions and capture of decisions, centring on two periods of the Elizabetahn reign in Spain: the «Decada Moderada» and «Bienio progresista» (the progressiv period of two years).

Keywords: Codification, commissions of codes, 19th century, Isabel II of Spain.

Recepción original: 23/10/2012

Aceptación original: 29/10/2012

Sumario: I. La Comisión de Códigos de 1846 (1846-1854); I.1. Estructura organizativa; I.2. Asignación económica y presupuestaria; I.3. Cuestiones procedimentales; I.4. Supresión; I.5. La Comisión Especial de procedimiento civil de 1854; II. La comisión de 1854 (18541856); III. Conclusiones.

\section{LA COMISIÓN DE CÓDIGOS DE 1846 (1846-1854)}

Tras la aprobación de la Constitución de 1845 en España, los nuevos principios centralistas revertieron en una secuencia de reformas en la Administración, la Hacienda y la Justicia, tendentes a uniformidad y a la jerarquización de la que la codificación no pudo permanecer ajena ${ }^{1}$. El Decreto de 31 de julio de 1846 firmado por Joaquín Díaz Canaleja, durante el gobierno de Francisco Javier Isturiz, suprimió la Comisión de Códigos de 1843, sin siquiera haber aprobado su magna obra: el Código Penal de 1848². La razón alegada para la supresión fue la existencia de insuperables defectos organizativos, lo que impedía alcanzar los propósitos fundamentales para los que fue erigida: la publicación de los principales Códigos para la

\footnotetext{
${ }^{1}$ Este trabajo es una reelaboración del titulado «Comisiones de Códigos convocadas entre 1846 y 1856», publicado en el Homenaje a José Antonio Escudero, Madrid, editorial Complutense, 2012, tomo III, págs. 1031 a 1056.

${ }^{2}$ Sobre las circunstancias específicas de creación, funcionamiento y extinción puede verse SÁnchez González, M. D. del M., «La Comisión de Códigos (18431846)», Anuario de Historia del Derecho Español, 74 (2004), págs. págs. 291-331 y SÁNCHEZ GonZÁLEZ, M. D. del M., La codificación penal en España los códigos de 1848 y 1850, Madrid, Boletín Oficial del Estado, Centro de Estudios Políticos y Constitucionales, 2004.
} 
Monarquía, es decir, un Código penal, un Código civil y uno de procedimientos. En el fondo lo que parecía haber era una importante motivación económica: el excesivo costo presupuestario que el funcionamiento de la comisión producía a las arcas del Estado habida cuenta de que contaba con un considerable número de vocales que conservaban sus puestos de origen en la Administración de Justicia y a los que había que pagar su sueldo, junto al de las personas que estaban interinamente desempeñando sus cargos durante su estancia en la Comisión.

El sueldo de los vocales propició muchas especulaciones. Así en la Gaceta de 25/8/1843, n. ${ }^{\circ}$ 3260, se daba cuenta de la polémica en una reseña:

«Cuando en uno de nuestros anteriores artículos nos hemos ocupado de la Comisión nombrada por el gobierno para la formación de los nuevos códigos, nada dijimos acerca de un punto que ha llamado la atención de algunos de los periódicos de esta capital. Ha creído el diario á que nos referimos que el sueldo de 600 rs. de vn., asignado a cada uno de los individuos de la comisión, era un motivo de censura justa, puesto que se gravaban con el considerablemente los presupuestos. Creemos que la objeción es poco sólida, y que debe tomarse la cuestión desde más arriba: ó conviene ó no que los códigos se hagan, ó es preciso ó no que para ello se forme una comisión de personas entendidas, de hábiles profesores de jurisprudencia. En el primer caso la medida es mala, porque se emprende un trabajo innecesario y futil: en el segundo debe aceptarse con todas sus consecuencias naturales y precisas.

Que la formación de los Códigos es una necesidad urgente que reclaman todos los españoles á cuya noticia ha llegado la dispersión de nuestras leyes, la multitud de nuestras colecciones legales, y la imperfección de nuestra legislación criminal, así como la relativa a procedimientos, cosa es que no puede demostrarse: tal es su claridad que se halla fuera del terreno de toda discusión y toda disputa. Cierto es y muy cierto que nuestras antiguas colecciones encierran leyes admirables, profundamente filosóficas y dignas de admiración de todos los hombres entendidos, pero no es menos cierto que su dispersión, en una multitud de códigos voluminosos, todos en observancia, embaraza la administración de justicia, oscurece los derechos particulares, aumenta las dificultades de la profesión, y el peligro natural de cometer desaciertos que rodea siempre á toda institución humana. Ni lo es menos que la ciencia ha progresado infinito en la parte criminal y de procedimientos, en las cuales conservamos nosotros todavía, muchas de las antiguas disposiciones, que mezcladas con otras modernas, no todas atinadas, forman un todo oscuro, confuso y defectuoso.

Importa pues practicar la reforma, y de seguro es ella bastante para dar crédito a un Gabinete si la realiza, que es precisamente la 
razon que tendrán para oponerse los enemigos de la situación actual, á que se continúen los presentes trabajos comenzados, ó se comiencen los que sean necesarios. Pues si la reforma ha de ser digna de la época que alcanzamos y de los recuerdos que en esta materia tenemos de nuestros antepasados, preciso es que se haga con prolijo esmero y singular cuidado: necesario que empleen en ella su tiempo los dignos profesores encargados de tan importante trabajo abandonando, sino todos sus negocios y ocupaciones, una parte al menos considerable. ¿Y no merecen por esto ninguna indemnización? ¿No es justo, y sobre justo conveniente que el Gobierno les asegure una subsistencia decorosa para el tiempo que hayan de invertir en su comisión abandonando sus naturales quehaceres? Si por no haber previsto esta circunstancia no hubieran podido trabajarse con esmero los códigos, ó se hubiera tardado más de lo necesario, ¿no sería peor para el país, y de ello culpable el Gobierno?. Vease pues como está reducida la cuestión á saber si es ó no necesario, si es ó no urgente que se formen los códigos; pero una vez decidido este punto, que es á nuestros ojos claro y evidente, falta todo motivo de discusión y toda causa de descontento.

Por fortuna algunos de los señores que componen la comisión se hayan en circunstancias que les permiten renunciar sus sueldos: el pais y el Gobierno les agradecerán su generoso desprendimiento, y no hará una sola persona que dude por eso de su celo» ${ }^{3}$.

El trasfondo del problema es en realidad el debate acerca de la conveniencia de la codificación ${ }^{4}$.

No obstante lo cierto es que el número excesivo de componentes y el régimen interior de funcionamiento de la misma condicionaba la fluidez en las discusiones en el seno de la comisión, restringiendo la posibilidad de unidad a la obra resultante ${ }^{5}$. Por ello el decreto de supresión, además

${ }^{3} \mathrm{Y}$ es que en esa misma Gaceta se daba cuenta del agradecimiento de Gobierno provisional al Ministro de Gracia y Justicia y al Ministro de Hacienda por haber renunciado a su sueldo como miembros de la Comisión, en la Gaceta n. ${ }^{\circ} 3267$ de 1/9/1843 a Joaquín Escriche por idéntico motivo, en la Gaceta n. ${ }^{\circ} 3271$ de 5/9/1843, a José María Sánchez y Puig por renunciar a la gratificación 100 reales como auxiliar de la comisión y en la Gaceta n. . $^{\circ} 410$ de 15/1/1844 a Felipe Gómez Acevo por renunciar a su sueldo como vocal.

${ }^{4}$ Sánchez González, D. del M., «Codificación versus jurisprudencia: el debate sobre la codificación en las Cortes de mediados del siglo XIX», Revista Chilena de Historia del Derecho, 22 (2010), II, págs. 1301-1311.

5 «Señora: Por el decreto del gobierno provisional de 19 de agosto de 1843 fue creada una comisión con el cargo especial de formar los Códigos, señalándose a sus individuos asignaciones harto considerables, que unos se apresuraron a renunciar, y que otros admitieron y siguen cobrando todavía. Los nombrados empezaron pronto sus trabajos, y dieron pruebas de su saber y celo, pero la organización que se dio a esta comisión hubo sin duda de ser defectuosa, cuando en cerca de tres años no ha podido aún presentar al Gobierno más que una parte de los proyectos que se la confiaron, a pesar de la asidua constancia con que sus individuos han trabajado por 
de eliminar también el sueldo de los auxiliares y del personal de asignado, reservaba al Ministerio la decisión de tomar las medidas oportunas para finalizar con los proyectos codificadores que estaban pendientes ${ }^{6}$. Aún así resultan curiosas las manifestaciones de Francisco de Cárdenas Espejo de que no existió motivo para la disolución, ya que el gobierno no lo alegó y por tanto no puede realizarse ningún juicio de valor sobre ello ${ }^{7}$.

La Comisión no cumplió con los objetivos fijados de acometer la Codificación civil, penal y procesal de forma unitaria evitando con-

espacio de tanto tiempo. Indagando las causas que hayan influido en esta lentitud, de presumir es no sea otra que el número excesivo de sus vocales, y el régimen interior de sus secciones; porque en trabajos científicos de tanta extensión la concurrencia muy numerosa de pareceres encontrados ofusca y prolonga sin término las discusiones, y priva a la obra de aquel concierto, sencillez y unidad que deben distinguirla. Ocupados por otra parte los más de los individuos que hoy componen la comisión en diversos cargos del Estado, se ven necesariamente distraídos por atenciones más inexcusables y perentorias; y así no es de extrañar que por estas causas no baste todo el celo y laboriosidad de tan doctos jurisconsultos, para terminar la formación de los proyectos con la perfección y la urgencia que el país tenía derecho a esperar al conceder para este fin abundantes recursos. Deseando pues, el Ministro que suscribe ocurrir a estos inconvenientes, y proponer oportunamente a V. M. el medio que tiene por más seguro y acertado de llevar a cabo la formación de los códigos, economizando gastos considerables, que en su mayor parte podrían ahorrarse, puesto que los trabajos de esta especie deben obtener a su tiempo recompensas de índole diferente, se atreve a someter a la Soberana aprobación de V. M. el siguiente proyecto de decreto. Madrid, 31 de julio de 1846. Señora A. L. R. P. de V. M.-El Ministro de Gracia y Justicia, Joaquín Díaz Canaleja» (exposición de motivos publicada por SERRANo GóMEZ, A., "El sesquicentenario de la Comisión de Códigos de 1843», Revista de Derecho Penal y Criminología, 3 (1993), págs. 9-17, págs. 12 y 13 infra).

${ }^{6}$ Los papeles se trasladaron al Ministerio, por lo que el decreto de supresión debería figurar en el Archivo de la Comisión General de Codificación (en adelante ACGC), Organización de la Comisión, leg. 1, carpeta 6, doc. 1 (en adelante sólo se indicará la sección si va referida a una distinta, incluyendo tras la referencia del archivo los números), pero no es así. La Comunicación oficial al Presidente de la Comisión se hizo el 1 de agosto de 1846, advirtiéndole de la necesidad de la entrega de los papeles (ACGC, leg. 1, carpeta 3, doc. 1). El Decreto puede verse en la Gaceta de Madrid de 2/8/1846, n. ${ }^{\circ} 4340$, habiéndose publicado con posterioridad en SERRANO GÓMEZ, "El sesquicentenario...», cit., pág. 13 y en SÁNCHEZ GonZÁlEZ, «La Comisión de Códigos...», cit., págs. 330-331.

Tan sólo el auxiliar Comisión José María Gorostidi, continuó en la percepción de su sueldo y ello debido a que fue comisionado para inventariar los papeles de la misma quedando bajo las órdenes del Presidente de la Comisión y del oficial del Ministerio Francisco Guerrero (ACGC, leg. 1, carpeta 3, doc. 1 y leg. 4, carpeta 1, doc. 127).

${ }^{7}$ CÁRdenas Espejo, F. de, Memoria histórica de los trabajos de la Comisión de Codificación suprimida por decreto del Regente del Reino de $1 .^{\circ}$ de octubre de 1869, escrita y publicada por acuerdo de la misma, siendo ponente $D$. — vocal de ella y seguida de varios apéndices, Madrid, Imprenta de la Revista de Legislación, 1871, pág. 9. Sobre dichos motivos véase ANTÓN ONECA, J., «El Código penal de 1848 y D. Juan Francisco Pacheco», Anuario de Derecho Penal y Ciencias Penales, 18 (1965), págs. 473-495, pág. 492 y Lasso Gaite, J. F., Crónica de la Codificación española T.5, Vol. I-II Codificación penal, Madrid, Ministerio de Justicia, 1970, I, pág. 309. 
tradicciones entre estas obras, en un intento de presentarlos juntos para su aprobación, lo que acarreó innumerables problemas para la propia estructura organizativa judicial que se vio desbordada con el tema ${ }^{8}$. Pero no nos parece que esos factores fueran los determinantes para la supresión, por cuanto nada más pasar el verano, un Decreto firmado por el mismo Joaquín Díaz Canalejas con fecha de 11 de septiembre de 1846 nombraba una nueva Comisión, curiosamente bajo la presidencia del mismísimo Bravo Murillo9:

«Al suprimir por mi Real Decreto de 31 de julio próximo la comisión de Códigos, cuyo celo, inteligencia y laboriosidad reconocí entonces y tendré presente para atender en la oportunidad al mérito de sus individuos, me reservé proveer lo conveniente para la más pronta y acertada conclusión de los proyectos de Códigos no redactados todavía; y en conformidad de esta reserva vengo en decretar los siguiente:

Artículo $1 .^{\circ}$ Los indicados trabajos que son de suyo tan delicados como importantes, se confían a una nueva comisión, que se dividirá en dos secciones, una de Código civil y otra de procedimientos civiles y criminales.

Art. 2. ${ }^{\circ}$ Nombro para componer esta comisión a D. Juan Bravo Murillo, presidente; D. Florencio García Goyena, D. Claudio Antón de Luzuriaga, D. Pedro Jiménez Navarro, D. Manuel de Seijas Lozano y D. Manuel Pérez Hernández.

Art. 3. ${ }^{\circ}$ Ninguno de los vocales de esta comisión percibirá sueldo ni gratificación alguna por este concepto: los méritos que espero contraigan en ella serán recompensados oportunamente.

Dado en Palacio a 11 de setiembre de 1846.-Está rubricado de Real mano.-El Ministro de Gracia y Justicia, Joaquín Díaz Canaleja.»

$¿$ Se trataba verdaderamente de que la necesidad de atender a sus puestos impedía la frecuencia de las reuniones, como se alegó en el decreto de supresión, o más bien de hacer una comisión más flexible a las necesidades de su presidente? Recordemos que el asignar un sueldo a los vocales tenía precisamente por finalidad el evitar que éstos tuvieran que ganarse el sustento, e incluso preocuparse por la pérdida de su trabajo anterior, ya que se pagaba a sus sustitutos. Debieron existir abusos en el disfrute de las licencias cuando el go-

${ }^{8}$ Véase al respecto SÁnchez GonzÁLEz, M. D. del M., «Las repercusiones de las reformas penales de 1848 en la Administración de Justicia», en Reformistas y reformas en la Administración española. III Seminario de Historia de la Administración, Madrid, INAP, 2005, págs. 353-359, donde se analizan los efectos de la falta de dicha adecuación.

${ }^{9}$ ACGC, leg. 1, carpeta 6, doc. 7 y Gaceta de Madrid de 13/9/1846, n. ${ }^{\circ} 4382$. Incluido también en SERRANO GÓMEZ, «El sesquicentenario...», cit. 
bierno procedió a retirarlas a los vocales para agilizar los trabajos de la Comisión. Pero también es evidente que si no se designaba sueldo para los vocales, éstos tendrían que compartir su actividad con sus ocupaciones laborales ordinarias, pues la gratificación posterior autorizada no sería suficiente para subsistir a las necesidades cotidianas.

Las dificultades procedimentales debidas al numeroso número de miembros sí parece más razonable como motivo de extinción de la Comisión. Y pese a todo hemos de recordar que en tres años se elaboraron las bases generales de toda la codificación, las bases específicas para cada codificación, el Código penal que había sido remitido al Gobierno y no había sido publicado, el libro I del Código civil y un proyecto de organización de los Tribunales ${ }^{10}$, además de que la Comisión tuvo que hacer frente a que desde el gobierno se le solicitasen de forma continúa proyectos que ocupaban a sus miembros en otros menesteres, como el proyecto de ley de orden público encargado el 7 de marzo de $1846^{11}$.

La aprobación de un proyecto de ley constitutiva de los tribunales por la Comisión, que lleva por fecha 12 de junio de $1846^{12}$, pudo encontrarse en la base de la disolución por cuanto fue remitido al gobierno junto con el voto particular de Bravo Murillo -además de otro de Domingo María Vila, con un proyecto paralelo ${ }^{13}-$, contrario al sentir de la mayoría de la Comisión de permitir el juicio oral en los procedimientos criminales, al menos temporalmente por considerar que podría acarrear gravísimos inconvenientes y perjudicar a la Administración de justicia, proponiendo en consecuencia rehacer el proyecto ${ }^{14}$. Esta discrepancia de Bravo Murillo con el resto de la Comisión pudo tener algo que ver con la posterior supresión de la misma, pues reflejan diferencias ideológicas importantes en su seno. El autoritarismo de Bravo Murillo empezaba a dar muestras de lo que luego sería su forma normal de ac-

${ }^{10}$ La Gaceta de Madrid recogía el 10/7/1846 la Comunicación de la Comisión de Códigos al Gobierno de que el Proyecto de ley constitutiva de los tribunales estaba definitivamente redactado y aprobado.

${ }^{11}$ Véase SÁnchez GonZÁLEZ, «La Comisión de Códigos...», cit., pág. 320.

${ }^{12}$ El traslado con el dictamen particular de Bravo Murillo en ACGC, leg. 4, carpeta 1 , doc. 126.

${ }^{13}$ Un resumen del proyecto de Vila puede verse en Crónica de la Codificación española. Vol. 1, Organización judicial, Madrid, Ministerio de Justicia, 1970.

${ }^{14} \mathrm{Al}$ parecer los máximos defensores de la medida fueron Pacheco y Seijas, mientras que Bravo Murillo señalaba la conveniencia de revisar todo lo actuado tomando como base el juicio escrito, siguiendo la tradición legislativa. Bravo Murillo en su escrito señala cómo, pese a defender la medida, Pacheco y Seijas eran partidarios de una introducción progresiva ensayándolo parcialmente en alguna provincia para valorar sus resultados. 
tuar. Además ya estaba redactado el Código penal, que Bravo Murillo conservaba y que presuntamente modificó a su antojo mientras estuvo en su poder, y se había avanzado bastante en los campos civil y procesal, por lo que no se necesitaban tantos vocales. No obstante hay quien como Martínez Alcubilla considera que en rigor debe considerarse a esta Comisión como una continuación de la primera Comisión ${ }^{15}$.

\section{I.1. Estructura organizativa}

El personal de la nueva Comisión estaba formado por los vocales y un numero de auxiliares designados para su actividad.

La mayoría de los vocales procedían de la anterior Comisión: su Presidente Bravo Murillo, su Vicepresidente Manuel Seijas Lozano, Florencio García Goyena, Claudio Antón de Luzuriaga y Manuel Pérez Hernández ${ }^{16}$. A ellos se les incorpora Pedro Jiménez Navarro, careciendo todos de sueldo ${ }^{17}$.

Un hecho muy significativo fue el nombramiento de Bravo Murillo como Ministro de Gracia y Justicia durante el gobierno del Duque de Sotomayor, en enero de 1847, ya que se produjo la circunstancia, insólita hasta ese momento en la codificación española, de que no dejó de presidir la Comisión, e incluso, pese a ser nombrado en octubre de 1849 Ministro de Hacienda bajo el gobierno de Ramón M. ${ }^{a}$ Narváez, seguía ocupando dicho puesto, lo que indudablemente suponía colocar a la Comisión bajo el poder del gobierno y politizarla perdiendo la independencia de que hasta entonces había disfrutado ${ }^{18}$.

${ }^{15}$ Diccionario de la administración española, peninsular y ultramar: compilación ilustrada de la novísima legislación de España en todos los ramos de la administración pública, 12 vols., Madrid, Administración, 1868-1870, vol. II, pág. 662.

${ }^{16}$ ACGC, leg. 2, carpeta 1, docs. 3, 5, 6, 10 y 11 .

${ }^{17}$ Antequera, J. M., La codificación moderna en España, Pamplona, Analecta, 2002., pág. 61; ANTÓN ONECA, «El Código penal de 1848», cit., pág. 492; CANDIL JiMÉNEZ, F., «Observaciones sobre la intervención de don Joaquín Francisco Pacheco en la elaboración del Código penal de 1848", Anuario de Derecho Penal y Ciencias Penales, 28 (1975), págs. 405-441, pág. 422; LASso GaITE, Codificación penal..., cit., I, pág. 309.

${ }^{18}$ Bravo Murillo, según da cuenta él mismo, fue sustituido como vocal por Manuel García Gallardo, consejero ordinario del Consejo Real (Escrito de Bravo Murillo de 5 de febrero de 1847, ACGC, leg. 2, carpeta 1, doc. 3). De la continuidad de Bravo Murillo en la Presidencia de la Comisión, y del nombramiento de García Goyena como Vicepresidente daba cuenta la Gaceta, número 4528 del sábado 6 de febrero de 1847. Respecto de Manuel García Gallardo se da cuenta de su nombramiento por la Reina el 5 de febrero de 1847 (ACGC, leg. 2, carpeta 1, doc. 15) y lo mismo respecto de Manuel Ortiz de Zúñiga (ACGC, leg. 2, carpeta 1, doc. 19). El Real decreto disponiendo que el Ministro de Gracia y Justicia D. Juan Bravo Murillo conserve la presidencia de la comisión de códigos, y nombrando vicepresidente de la misma á D. Florencio García Goyena, individuo de la misma comisión y el Real decreto de 1/2/1847 nombrando a D. Manuel Ortiz de Zúñiga y a D. Manuel García Gallardo 
Y aunque salió de la comisión en 1847, al finalizar su etapa ministerial volvió a integrarse en la Comisión ${ }^{19}$.

También en enero de 1847 abandonó momentáneamente la Comisión Manuel de Seijas Lozano, por haber sido nombrado Ministro de Gobernación en el mismo gobierno, siendo sustituido por Manuel Ortiz de Zúñiga $^{20}$, no así en la Vicepresidencia para la que Bravo Murillo colocó a Florencio García Goyena ${ }^{21}$, que quedaría en dicho puesto al regreso de aquél ${ }^{22}$. Fue también Bravo Murillo el que pidió la reincorporación de Seijas a la Comisión una vez que éste a su vez dejó de ser Ministro de Gobernación, siendo nombrado de nuevo vocal el 8 de mayo de $1847^{23}$.

En enero de 1848 consta que el número de vocales había aumentado hasta diez, contando al Presidente Bravo Murillo y al Vicepresidente García Goyena. Esta circunstancia se debe al regreso de Seijas, a la continuidad de quien fue su sustituto Manuel García Gallardo, y a la incorporación de Manuel Ortiz de Zúñiga y Francisco Gamero Cívico y Benjumea y de Vicente Valor ${ }^{24}$, constando en los archivos que Ortiz de Zúñiga y Claudio Antón de Luzuriaga contaban con sueldo, quizás debido a que en los dos se daba la circunstancia de disfrutar de una cesantía ${ }^{25}$. Continúa en la Secretaría de la Comisión José María Sánchez Puig, secretario de la anterior Comisión, pero además existe

vocales de la comisión de códigos, en lugar de D. Manuel de Seijas Lozano y D. Juan Bravo Murillo pueden verse en la Gaceta de Madrid de 6/2/1847, n. ${ }^{\circ} 4528$.

${ }^{19}$ ACGC, leg. 2, carpeta 1, doc. 5.

${ }^{20}$ Sobre el mismo véase SÁnchez González, M. D. del M., «Historiografía penal española (1808-1870): la escuela clásica española», en Alvarado Planas, J. y SERRANO Maíllo, A., Estudios sobre el desarrollo histórico del Derecho penal y la Criminología, Madrid, Dikinson, 2007, págs. 69-129. En el caso específico de Manuel Ortiz de Zúñiga entró en la Comisión con el sueldo de 50.000 reales anuales que disfrutaba en su último destino como subsecretario del Ministerio (ACGC, leg. 2, carpeta 1, doc. 19).

${ }^{21}$ ACGC, leg. 2, carpeta 1, doc. 10.

22 «Relación del personal y retribuciones de la Comisión que preside D. Juan Bravo Murillo» (ACGC, leg. 1, carpeta 7, doc. 3) y también en un escrito de Bravo Murillo de 5 de febrero de 1847 (ACGC, leg. 2, carpeta 1, doc. 3) y en ACGC, leg. 2, carpeta 1, doc. 5. El Decreto con la solicitud de continuación en supuesto de vocal y vicepresidente lleva fecha de 5 de octubre de 1847 (ACGC, leg. 2, carpeta 1, doc. 10, y Gaceta de Madrid de 8/10/1847, n. ${ }^{\circ}$ 4772). Véase ANTEQUERA, La codificación moderna..., cit., págs. 61-62.

${ }^{23}$ Escrito de Bravo Murillo de 23 de abril de 1847 (ACGC, leg. 2, carpeta 1, doc. 5).

${ }^{24}$ De Francisco Gamero consta como fecha de nombramiento el 28 de agosto de 1947 (ACGC, leg. 2, carpeta 1, doc. 27), y de Vicente Valor, Regente de la Audiencia Territorial de Madrid, la de 16 de octubre de 1947 (ACGC, leg. 2, carpeta 1, doc. 28 y Gaceta de Madrid de 17/10/1847, n. ${ }^{\circ}$ 4781). ANTEQUERA, La codificación moderna..., cit., pág. 62.

${ }^{25}$ ACGC, leg. 1, carpeta 7, doc. 3. 
un Vicesecretario, puesto ocupado por Miguel Bataller, y seis auxiliares: Alvaro Santillana Guerra, Juan Bautista Cavaller ${ }^{26}$, Cosme Barrio Miguel, Eduardo López Pelegrín, Facundo Cortadellas y José Villegas Cevallos -Sánchez Puig, Santillana Guerra, Cortadillas y López Pelegrin, procedían de la anterior comisión-. Junto a ellos figura el portero Francisco García de Palomino ${ }^{27}$ que ya lo fue de la anterior.

En una comunicación que el 30 de octubre de 1850 hizo el Vicepresidente al Ministro de Justicia se manifestaba que en abril de 1850 se había terminado con la redacción del Código de procedimiento criminal, aprobándose en mayo buena parte del articulado, y que del procedimiento civil faltaba sólo armonizar el articulado con el Código civil, habiendo sido este último revisado definitivamente el 21 de diciembre, por lo que se consideraba la codificación lo suficientemente avanzada como para rebajar la consignación presupuestaria dedicada al personal a 60.000 reales y suprimir parte del mismo al no ser necesaria tanta ayuda. De ahí que el 29 de diciembre de 1850 se reforme la Comisión mediante la supresión de los auxiliares Miguel Bataller, Alvaro Santillana, Juan Bautista Cavaller, José Villegas y Cosme Barrio ${ }^{28}$, funcionando desde entonces la Comisión con el secretario Sánchez Puig, dos auxiliares -López Pelegrín y Cortadillas, los más antiguos de entre los de menor sueldo-, y constando expresamente que de ser necesaria la ayuda de más personas se facilitaría personal de Ministerio ${ }^{29}$.

Esta composición ${ }^{30}$ figura alterada en noviembre de 1852 por cuanto el nombre de Pablo Jiménez Navarro aparece tachado y en cambio se han añadido tres personas más -Joaquín José Casaus,

${ }^{26}$ La Gaceta de Madrid de 1/9/1847, n. ${ }^{\circ} 4735$, daba la siguiente noticia: «Hemos sabido con agrado la promoción de D. Juan Bautista Caballer, abogado de los tribunales del reino y del colegio de la ciudad de Valencia, á oficial primero auxiliar de la comisión de Códigos».

${ }^{27}$ «Relación del personal y retribuciones de la Comisión que preside D. Juan Bravo Murillo» (ACGC, leg. 1, carpeta 7, doc. 3).

28 «Supresión de auxiliares» (ACGC, leg. 1, carpeta 7, doc. 1). Por un error en el catálogo del Archivo figura la fecha de 1846 y en verdad que el trazo del número no figura claro pero hay que relacionar este documento con otros que figuran en la misma carpeta referentes a 1850 , escritos por la misma persona en los que claramente se ve que se trata de un 5 y no un 4 y del texto de dichos documentos se deduce que la fecha debió ser 1850.

${ }^{29}$ «Relación del personal y retribuciones de la Comisión que preside D. Juan Bravo Murillo» (ACGC, leg. 1, carpeta 7, doc.3).

${ }^{30}$ Se conservaba en una relación del personal de la Comisión enviada el 26 de noviembre de 1849 debido a la necesidad de enviar información para la formación de la guía de viajeros (ACGC, leg. 1, carpeta 8, doc. 1.). 
Pablo Govantes ${ }^{31}$ y Francisco Cárdenas ${ }^{32}-$, que fueron agregados a la sección para la discusión de los expedientes relativos a la reforma del Código penal ${ }^{33}$. En la información enviada en noviembre de $1853^{34}$, además de desaparecer de la lista Bravo Murillo, figura al

${ }^{31}$ Pablo Govantes Fernández nació en Foncea (Logroño) el 30 de junio de 1785. Sus estudios de Leyes se realizaron en las Universidades de Santiago y Valladolid, recibiendo los grados de Licenciado y Doctor. Ejerció como abogado en la Chancillería de Valladolid y recibió el encargo de las cátedras de Economía Política y de Historia y elementos de Derecho Civil de Roma, en la Universidad de esta última ciudad desde 1816 hasta 1819 , perteneciendo como colegial mayor y consiliario al Colegio de Santa Cruz. En 1827 era Doctor Catedrático de instituciones de Derecho Civil. En Burgos fue Diputado provincial y Secretario de la Diputación, pasando al puesto de oficial de la Secretaría de Gobernación de la Península. Ejerció como Alcalde del Crimen en la audiencia de Barcelona en 1834, pasando en 1835 como Magistrado a la de Zaragoza, en 1843 a la de La Coruña y a la de Burgos, de las que fue Regente, y a la de Madrid. En 1852 fue nombrado Magistrado del Tribunal Supremo, aunque se jubiló por problemas de salud en 1856. También fue diputado entre 1837 y 1846 y senador vitalicio desde 1845 a 1868 . Fue Ministro de Gracia y Justicia del 14 de abril de 1853 al 19 de septiembre de 1853 bajo la presidencia del Teniente General Francisco Lersundi [Véase Lasso Gaite, El Ministerio de Justicia. Su imagen histórica (1714-1981), Madrid, Ministerio de Justicia, 1984, págs. 98-99].

${ }^{32}$ Francisco de Cárdenas y Espejo nació en Sevilla en 1817, siendo ordenado in sacris tras realizar la carrera eclesiástica y la de leyes en su ciudad natal. Fue además Catedrático de Ética y periodista, llegando a dirigir El Conservador-destruido en 1840 por su publicación de un artículo contra el régimen del general Espartero- y fundando la Revista Andaluza, además de la Enciclopedia del siglo XIX, El Derecho -1844-, El Derecho Moderno -1847-1853- y la Revista General de Legislación y Jurisprudencia -1854-. Precisamente su nombramiento para miembro de la Comisión se produce gracias a unos artículos acerca de la reforma penal publicados en El Derecho Moderno en 1851. Precisamente de su participación intensa surge su obra Memoria Histórica de los trabajos de la Comisión de Codificación en 1871. Fue Diputado, Senador, Diputado general de Gobernación, Subsecretario de Gobernación, Director General de Ultramar, Consejero de Hacienda y Gobernador del Banco Hipotecario. Accedió a la Cartera de Gracia y Justicia con la Restauración en 1875, derogando la Ley de Matrimonio Civil, y firmando otras muchas disposiciones importantes. Su producción jurídica es también notable siendo autor de numerosas obras de entre las que destacamos su Ensayo sobre la historia de la propiedad territorial en España, Madrid, 1872. Muere en 1898. (Ibid., págs. 141-142).

${ }^{33}$ ACGC, leg. 1, carpeta 8, doc. 4. Joaquín José Casaus era por esas fechas Ministro del Tribunal Supremo y Pablo Govantes Regente de la Audiencia de Madrid. Respecto de Francisco Cárdenas la razón de su incorporación se debe a la presentación de documentación tenida por importante en la mencionada reforma a juicio del Ministro González Romero (ACGC, leg. 2, carpeta 1, doc. 29). ANTEQUERA da cuenta de la incorporación (ANTEQUERA, La codificación moderna..., cit., pág. 62). Consta en el expediente una declaración oficial de nombramiento realizada por Real orden de 8 de diciembre de 1853, firmada por el marqués de Gerona, y como fecha de toma de posesión como vocal el 14 de enero de 1854 (ACGC, leg. 2, carpeta 1, docs. 29, 30 y 31 ).

${ }^{34}$ ACGC, leg. 1, carpeta 8, doc. 5. 
frente de la Comisión su Vicepresidente García Goyena, y aparecen como nuevos vocales Felipe Rull y Castaños $^{35}$ y Tomás María Viz$\operatorname{manos}^{36}$, constando como agregados, Joaquín Melchor y Pinazo ${ }^{37}$, el marqués de Gerona José de Castro y Orozco ${ }^{38}$, Andrés Juez Sarmiento ${ }^{39}$ y Antonio Escudero ${ }^{40}$. Todos ellos fueron incorporados para adelantar el trabajo de la reforma del Código penal.

La última composición sin fechar, sería posterior a noviembre de 1853, que es cuando se envía la relación para la formación de la guía

${ }^{35}$ Regente cesante de la Audiencia de Manila. Fue nombrado vocal de la Comisión el 16 de junio de 1853 (ACGC, leg. 2, carpeta 1, doc. 34). ANTEQUERA llama a este vocal Felipe Rus e indica la fecha de incorporación (ANTEQUERA, La codificación moderna..., cit., pág. 62).

${ }^{36}$ Tomás M. ${ }^{\text {a }}$ Vizmanos se incorporó a esta Comisión el 27 de octubre de 1853, quedando agregado a la sección de reforma del Código penal (ACGC, leg. 2, carpeta 1, doc. 21). Junto con Cirilo Álvarez publicó unos atinados Comentarios al nuevo Código penal, 2 Vols., Madrid: [s. n.], 1848 (Tipág. de J. González y A. Vicente).

${ }^{37}$ Regente de la Audiencia de Albacete. La razón de su entrada en la Comisión se encuentra en sus trabajos sobre el Código penal y el deseo de que fueran analizados en la Comisión, de ahí que al principio conste su condición de agregado a la Comisión revisora del Código penal mientras duraban las vacaciones judiciales. La fecha de la comunicación al presidente de la Comisión es de 6 de julio de 1851 y va firmada por González Romero. La orden de su nombramiento como vocal es del marqués de Gerona y lleva fecha de 8 de diciembre de 1853, de ahí que la toma de posesión como vocal lleve fecha de 20 de enero de 1854 (ACGC, leg. 2, carpeta 1, doc. 32).

${ }^{38}$ José de Castro Orozco, por aquel tiempo Regente de la Audiencia de Sevilla, fue agregado como auxiliar el 8 de abril de 1853 y fue declarado oficialmente vocal de la misma, al igual que los demás el 8 de diciembre de 1853, de ahí que tomase posesión como vocal el 20 de enero de 1854 (ACGC, leg. 2, carpeta 1, doc. 33). La fecha de la incorporación la recoge Antequera sin dar más datos (ANTEQuERA, La codificación moderna..., cit., pág. 62. Véase además SÁNCHEz GonzÁlez, "La Comisión de Códigos...», cit., págs. 311, 313 y 321 y Lasso Gaite, El Ministerio de Justicia..., cit., págs. 98-99). Sobre el mismo SÁNCHEZ GonZÁLEZ, "Historiografía penal española...», cit., págs. 91-92).

${ }^{39}$ Presidente de Sala de la Audiencia de Mallorca. Fue nombrado agregado el 8 de septiembre de 1853 para cubrir la vacante producida por Govantes el 14 de abril de 1843 al ser designado Ministro de Justicia. Al igual que los otros agregados fue declarado vocal el 8 de diciembre de 1853, tomando posesión el 20 de enero de 1854 . Solicitó la renuncia por enfermedad y que se le declarase cesante con el sueldo que le correspondiente según su clasificación, renuncia que no fue admitida y fue sustituida por cuatro meses de licencia para restablecer su salud el 12 de mayo de 1854 (ACGC, leg. 2, carpeta 1, doc. 35). Antequera consigna la fecha (ANTEQUERA, La codificación moderna..., cit., pág. 62).

${ }^{40}$ Regente de la Audiencia de Albacete. El 8 de diciembre de 1853 se ordenaba su incorporación como agregado y su permanencia en la Corte, siendo designado como vocal el 8 de diciembre de 1853 y tomando posesión el 20 de enero de 1854. El 19 de marzo de 1854 se le concedían dos meses de licencia por motivos de salud (ACGC, leg. 2, carpeta 1, doc. 36). La fecha de su incorporación dada por Antequera es la de 29 de octubre de 1853 (Ibid., pág. 62). LASSO consigna que también fue Subsecretario de Justicia (Lasso GaITE, Codificación penal..., cit., I, pág. 384). 
de viajeros, y es la siguiente ${ }^{41}$ : Florencio García Goyena, Claudio Antón de Luzuriaga, Manuel de Seijas Lozano, Manuel Pérez Hernández, Manuel García Gallardo, Manuel Ortiz de Zúñiga, Francisco Gamero y Cívico Benjumea, Vicente Valor, Joaquín José Casaus, Francisco de Cárdenas, Joaquín Melchor y Pinazo, José de Castro y Orozco, Felipe Rull y Castaños, Andrés Juez y Sarmiento, Tomás M. ${ }^{a}$ Vizmanos, Antonio Escudero, José Antonio Olañeta ${ }^{42}$ y Joaquín Roncalii ${ }^{43}$. Constan además Laureano Rojo de Norzagaray ${ }^{44}$, como agregado, José M. ${ }^{a}$ Sánchez y Puy como Secretario, los dos auxiliares Felipe Nero y Salamanca y Caballero Infante, los dos escribientes Mariano Martín Parici y Antonio La Riba y el portero Francisco García Palomino. Esta es la primera vez que figuran los escribientes en una relación del personal.

Curiosamente volvemos a los 18 miembros de la Comisión de 1843, que en realidad son 19 -el agregado es un vocal provisional que se termina incorporando-, lo que supone la falsedad de la alegación realizada del elevado número de personas como causa de la supresión.

\section{I.2. Asignaciones económicas y presupuestarias}

De la relación de personal y retribuciones realizada en enero de 1848, consta que dos de los diez vocales cobraban sueldo: Claudio Antón de Luzuriaga cobraba 10.000 reales, además de 40.000 reales por cesantía; y 25.000 reales Manuel Ortiz de Zúñiga, además de 25.000 que también cobraba por cesantía. Respecto de los auxiliares el secretario Sánchez Puig cobraba 12.000 reales, el Vicesecretario Bataller 12.000 reales, los auxiliares Santillana y Cavaller 9.000 reales cada uno y 5.000 reales los cuatro restantes, mientras que el portero presenta la misma asignación que se le designó en 1843, 2.920 reales. Además en la relación figura una partida de 12.000 reales para gastos, lo que supondrían un total de 109.920 reales de gasto por el total funcionamiento de la Comisión ${ }^{45}$.

${ }^{41}$ ACGC, leg. 1, carpeta 8, doc. 6.

${ }^{42}$ Olañeta era fiscal del suprimido Consejo de Ultramar y se incorporó el 24 de noviembre de 1853 (ACGC, 2, 1, 37); ANTEQUERA, La codificación moderna..., cit., pág. 62.

${ }^{43}$ Joaquín Roncali, ministro del Tribunal Supremo, fue nombrado vocal de la Comisión el 24 de mayo de 1854.

${ }^{44}$ Laureano Rojo de Norzagaray fue Presidente de Sala de la Audiencia de Oviedo y se incorporó a la Comisión mientras disfrutaba de una licencia el 29 de abril de 1854 (ACGC, leg. 2, carpeta 1, doc. 38).

45 «Relación del personal y retribuciones de la Comisión que preside D. Juan Bravo Murillo» (ACGC, leg. 1, carpeta 7, doc. 3). 
Dada la reforma realizada el 29 de diciembre de 1850 suprimiendo cinco auxiliares, la reducción de gastos supone un ahorro importante, por lo que figura una asignación de 60.000 reales para personal $^{46}$, de forma que el 1 de enero de 1851 se enviaba un oficio al Ministerio de Justicia en el que constaba que el presupuesto de personal de la Comisión había quedado reducido a 60.000 reales, habiendo ordenado la Reina que dicha cantidad se repartiera entre los individuos que formaban parte de ella, tal y como se venía haciendo, es decir, los vocales Claudio Antón de Luzuriaga y Manuel Ortiz de Zúñiga cobraron respectivamente 10.000 y 25.000 reales, el secretario José María Sánchez Puig 12.000 reales, los auxiliares Facundo Cortadellas y Eduardo López 5.000 reales cada uno y 2.920 reales el portero Francisco García Palomino ${ }^{47}$. A parte seguían constando 12.000 reales destinados a gasto de material.

Luego la reducción presupuestaria no parece ser tampoco la verdadera causa de la supresión de la Comisión de 1843.

\section{I.3. Cuestiones procedimentales}

Al haber terminado la Comisión de 1843 la codificación penal, cuyo texto se encontraba en el Ministerio de Bravo Murillo esperando la autorización para presentar a las Cortes el proyecto de Código Penal ${ }^{48}$, la Comisión sólo se dividió en dos secciones: una civil y una de procedimientos.

Pero la remisión frecuente de encargos específicos por parte del Ministerio, motivados por los continuos cambios de titular, repercutió en la actividad de la Comisión. Así José María de Antequera da cuenta de cómo el 14 de enero de 1847 se encargó a la Comisión analizar un proyecto de decreto sobre organización y atribuciones del Ministerio fiscal remitido por el Tribunal Supremo y el 8 de octubre la formación de un proyecto de ley con los requisitos para el ejercicio del cargo de Juez o Magistrado ${ }^{49}$, a la vez que el 8 de octubre de 1849

${ }^{46}$ Idem.

${ }^{47}$ ACGC, leg. 1, carpeta 7, doc. 2.

${ }^{48}$ Lasso Gaite, Codificación penal..., cit., I, pág. 309. Curiosamente sólo José María Antequera indica que el Código penal estaba "casi terminado», encargándose esta comisión de su finalización (ANTEQUERA, La codificación moderna..., cit., pág. 61).

${ }^{49}$ Gaceta de Madrid, 9/10/1847, n. ${ }^{\circ}$ 4773: «Teniendo en consideración las razones que me ha expuesto mi Ministro de Gracia y Justicia, vengo en decretar lo siguiente:

1. En puntual cumplimiento de los artículos 67, 69 y 70 de la Constitución del 
se le apremiaba acerca de la terminación del Código de procedimiento criminal. Pese a eso logró sacar adelante los trabajos primordiales remitiendo al gobierno el 21 de diciembre de 1849 un proyecto de ley de organización, competencia y facultades de los tribunales y el 6 de diciembre de 1850 el proyecto de Ley de Enjuiciamiento civil -Código de actuación civil- redactado por Manuel García Gallardo ${ }^{50}$. También se

Estado, mi Ministro de Gracia y Justicia someterá a mi aprobación, y presentará a la de las Cortes en las primeras sesiones de la próxima legislatura, un proyecto de ley que fije definitivamente las circunstancias y requisitos necesarios para ser nombrado juez o magistrado, los casos de responsabilidad de estos y su inamovilidad, conforme á los citados artículos constitucionales.

2. ${ }^{\circ}$ En las propuestas que para fiscales, jueces y magistrados tuvieren lugar hasta la promulgación de dicha ley se observará inalterablemente lo dispuesto en el decreto de 29 de diciembre de 1838. Dado en Palacio a 8 de octubre de 1847. Rubricado de la Real Mano.-El Ministro de Gracia y Justicia, Lorenzo Arrazola».

A continuación figura la encomienda a la Comisión, tal y como suponemos que ocurrió en el resto de los supuestos: «Extimado Sr.: Para el más acertado cumplimiento del Real Decreto de este día sobre responsabilidad e inamobilidad de los jueces, del que acompaña copia, S. M. se ha dignado mandar que la comisión de Códigos, con preferencia a otros trabajos, teniendo presente la organización actual de los tribunales, y lo que aun podría tardar en presentarse y aprobarse por las Cortes la que pueda creerse más conveniente y está sometida a esa comisión, formule y remita a este ministerio el proyecto de ley que crea más a propósito para que se realicen cumplidamente las saludables miras de S.M. consignadas en el mismo.

Dicho proyecto de ley deberá contener las bases y resolver los puntos siguientes:

1. Circunstancias y requisitos indispensables para ser nombrado juez ó magistrado.

2. ${ }^{\circ}$ Los necesarios asimismo para los ascensos graduales y promociones en la carrera.

$3 .^{\circ}$ Las causas que autoricen la suspensión, traslacion y jubilación de un juez ó magistrado.

4. ${ }^{\circ}$ Los casos de responsabilidad y forma de exigirla con la correspondiente escala penal.

5. ${ }^{\circ}$ Lo relativo á la inamovilidad constitucional de jueces y magistrados.

6. Si impuesta por sentencia á un juez ó magistrado la privación de oficio, habrá lugar á la reabilitación, y en su caso la forma y circunstancias para que tenga efecto.

Con todo lo demas que á la comisión se le ofrezca y parezca para conseguir los fines indicados en el Real Decreto, extendiendo en dictamen separado y razonado lo que no fuese objeto de ley, y no siendo extensivo su informe á los fiscales y promotores por corresponder lo que a ellos pertenece á la organización especial de dicho ministerio público.

De Real Orden lo digo a V.E. para su inteligencia y cumplimiento. Dios guarde a V. E. muchos años. Madrid 8 de octubre de 1847.-Arrazola.-Sr. Presidente de la comisión de códigos».

${ }^{50}$ ANTEQUeRA, La codificación moderna, pág. 77. No se conservan las actas con las discusiones pero sí un ejemplar del Código con las modificaciones introducidas tras los debates. Un análisis del mismo puede verse en JUAN Francisco Lasso GaITE, Crónica de la codificación española. vol. 2, Procedimiento civil, Madrid, Ministerio de Justicia, 1999, págs. 39-41. 
terminó la realización de un proyecto de ley sobre Amnistías, Indultos y Rehabilitaciones, que redactaron Pedro Jiménez Navarro y Francisco Gamero y Cívico Benjumea y que fue presentado a la Comisión el 5 de noviembre de 1848, para su examen y enviado al Ministerio el 2 de enero del año siguiente ${ }^{51}$. Joaquín Melchor Pinazo elaboró además un proyecto de ley sobre duelo, -el proyecto de ley para suprimir los desafíos-, elevado al gobierno el 13 de mayo de $1851^{52}$.

Tras la llegada al Ministerio de Justicia de Ventura González Romero, nombrado durante el gobierno de Juan Bravo Murillo, ordenó el 13 de marzo de 1851 a la Comisión la revisión del Código penal, de cara a cumplir lo establecido en la ley de 19 de marzo de 1848 y poder así presentar a la próxima legislatura el correspondiente proyecto de ley. Se trataba de la materialización de una duda importante existente en la mentalidad del legislador: la profunda transformación que las reformas extraparlamentarias habían operado en el Código de 1848. La respuesta de la Comisión, firmada por García Goyena consiste en señalar la imposibilidad de la medida al no existir datos suficientes en el seno de la Comisión para acometer la misma, por lo que solicitaba el envío de una circular a los tribunales con un cuestionario de 46 preguntas, para que la Comisión analizase las respuestas, lo cual se materializó mediante la Real Orden de 16 de abril de $1851^{53}$. No obstante, desde ese momento se estableció una sección dentro de la Comisión con el encargo de reformar el Código penal, a la que se incorporaron especialistas en la materia como Joaquín José Casaus, Pablo Casimiro Govantes -que fue sustituido el 14 de abril de 1853 tras su nombramiento como Ministro de Gracia y Justicia, en el gobierno de Francisco Alejandro Lersundi y Ormaechea, por Andrés Juez Sarmiento, Presidente de Sala de la Audiencia de Mallorca- y Francisco de Cárdenas, como ya indicamos. Y es que el Código de 1850 en vez de subsanar las deficiencias y erratas que el Código de 1848 presentaba, había introducido muchas más debido a las continuas alteraciones operadas en el mismo, tal y como el propio Cárdenas manifestó tras un exhaustivo y detallado informe ${ }^{54}$. A la Comisión se agregó, como ya manifestamos, Joaquín Melchor Pinazo, en función de ciertos trabajos que tenía realizados que se consideraban de utilidad.

El 5 de mayo de 1851 la Comisión presentaba al gobierno el proyecto de Código civil, que firmaban Bravo Murillo, Florencio García Goyena, Claudio Antón de Luzuriaga y José M. ${ }^{a}$ Sánchez

${ }^{51}$ Lasso Gaite, Codificación penal, I, pág. 410.

52 Ibid., I, pág. 410.

${ }^{53}$ Ibid., I, págs. 338-339.

${ }^{54}$ ACGC, leg. 18, carpeta 15. 
y Puy ${ }^{55}$, que el gobierno publicó en la revista El Derecho Moderno y presentó a la opinión de los Tribunales para que emitiesen su opinión antes del 1 de enero de 1852, pero sin aprobarlo ${ }^{56}$. Poco después el 17 de diciembre de 1852 se concedían cuatro meses de licencia a Bravo Murillo por su precaria salud, dimitiendo como Presidente el 27 de mayo de 1853, según él, por tener que ausentarse de la Corte ${ }^{57}$.

Siendo Ministro de Gracia y Justicia José Castro Orozco, marqués de Gerona, expidió una real orden el 4 de octubre de 1853 señalando el orden en que la Comisión debía trabajar ${ }^{58}$. El 18 de

${ }^{55}$ ANTEQuera, La codificación moderna..., cit., pág. 70. Antequera señala como al presentarlo Florencio García Goyena tenía preparada su obra Concordancias, motivos y comentarios del Código civil (Madrid, 1852), con la historia, examen comparado y contenido de cada artículo. En realidad un primer anteproyecto fue elevado el 10 de septiembre de 1849 (Lasso Gaite, J. F., Crónica de la Codificación española T.4, Vol. I-II Codificación civil, Madrid, Ministerio de Justicia, 1970, I, pág. 200).

${ }^{56}$ Antequera reproduce las razones alegadas por el Gobierno para no publicarlo que aparecieron, junto con el texto del Código en la revista El Derecho Moderno: "Considerando que no obstante que generalmente se haya limitado la Comisión á redactar clara y sencillamente, con notables mejoras, las disposiciones dispersas en varios cuerpos legales nacionales, decidiendo y aclarando muchos puntos ocritos ó controvertibles y destruyendo los abusos y malas prácticas introducidas en el foro por las vicisitudes de los tiempos, es siempre de suma gravedad y trascendencia toda obra de esta clase, porque sus disposiciones afectan esencialmente á las relaciones entre la familia y el orden social, la de las familias mismas y los particulares entre sí, reglando lo tocante á las transacciones y á los derechos é intereses privados de todos.

2. ${ }^{\circ}$ Que la existencia de fueros, legislaciones especiales, usos y costumbres varias y complicadas, no sólo en determinados territorios de la Monarquía que en otro tiempo formaron estados independientes, sino en no pocos pueblos pertenecientes á provincias en que por lo general se observan los Códigos de Castilla, aumenta considerablemente las dificultades y obstáculos que siempre ofrece la publicación y ejecución de todo Código general.

3. ${ }^{\circ}$ Que por lo mismo es conveniente y necesario que antes de tomar resolución definitiva... se discuta previamente por personas competentes para ello, se ilustre y se prepare la opinión y se reunan y adquieran los datos y conocimientos generales y locales... á fin de que los cuerpos colegisladores y el Gobierno de S. M. puedan apreciar debidamente las disposiciones de dicho proyecto é introducir en él las alteraciones y mejoras que aun puede ser susceptible... ha tenido á bien mandar S. M.» (ANTEQUeRA, La codificación moderna..., págs. 71-72). Lo cierto es que estas razones publicadas por Antequera conforman la Real Orden de 12/6/1851 dictando las reglas que han de observar los individuos de la comisión de Códigos, ordenando la publicación del Código en las Revistas El Derecho Moderno y la Revista de Jurisprudencia y Administración, que apareció en la Gaceta de Madrid de 14/6/1851, n. ${ }^{\circ}$ 6179. La traslación del escrito del Ministro de Gracia y Justicia a la Comisión se hizo el 30 de junio de 1851 y consta en ACGC, leg. 2, carpeta 1, doc. 3, págs. 24-30. El texto de 12 de junio de 1851 con el decreto puede verse en ACGC, leg. 2, carpeta 1, doc. 5.

${ }^{57}$ ACGC, leg. 2, carpeta 1, doc. 3.

${ }^{58}$ Lasso Gaite, Codificación civil..., I, pág. 291. 
octubre de 1853 el Presidente de la Comisión informaba al Ministerio de que pese al retraso en los trabajos de la Comisión, se había terminado con la elaboración de la ley constitutiva de los tribunales, el Código penal y el civil, faltando tan sólo por discutir el Código de procedimiento penal y terminar el de procedimiento civil, a fin de finalizar con los trabajos de la forma más rápida posible. Habida cuenta de la necesidad y el reclamo realizado por la opinión pública de su terminación para la posterior presentación a las Cortes, la Reina había autorizado la división de la Comisión en cuatro secciones independientes, mediante el Real Decreto de 14 de octubre de 1853 -a propuesta del Ministro Castro Orozco- para que trabajasen al mismo tiempo, con la finalidad de revisar la ley orgánica de los tribunales -sobre el proyecto de 23 de noviembre de 1850-, realizar la discusión de los códigos de procedimiento civil y del criminal, y el estudio de las reformas convenientes de realizar en los Códigos penal y civil en vista de las informes enviados por las Audiencias y Colegios de Aboga$\operatorname{dos}^{59}$. La relación de la distribución del personal en secciones que hemos encontrado es la siguiente ${ }^{60}$ :

1. Sección de Código civil.

Presidente: Florencio García Goyena.

Vocal: $\quad$ Claudio Antón de Luzuriaga.

Secretario: José M. ${ }^{a}$ Sánchez y Puy.

Auxiliar Felipe Nero y Salamanca.

2. Sección de Código penal.

Presidente: Manuel de Seijas Lozano.

Vocales: Joaquín José Casaus.

Tomás M. ${ }^{\mathrm{a}}$ Vizmanos.

José Antonio Olañeta.

Agregado: Laureano Rojo y Norzagaray.

Auxiliar: (sin nombre) Caballero Infante.

3. Sección de Procedimientos civiles.

Presidente: Manuel García Gallardo.

Vocales: Francisco Cárdenas.

Antonio Escudero.

Joaquín Roncali.

${ }^{59}$ ACGC, leg. 1, carpeta 9, doc. 1.

${ }^{60}$ ACGC, leg. 1, carpeta 8, doc. 6. 
4. Sección de Procedimiento criminal.

Presidente: Manuel Ortiz de Zúñiga.

Vocales: $\quad$ Felipe Rull y Castaños.

Andrés Juez Sarmiento.

Joaquín Roncali.

Estas dos últimas secciones actuaban reunidas a modo de comisión general bajo la presidencia de García Gallardo, para revisar la ley orgánica de los tribunales. No obstante esta clasificación presenta omisiones importantes pues sabemos que tanto Ortiz de Zúñiga como Domingo Ruiz de la Vega pertenecieron a la Sección civil y participaron en la discusión del texto de Código civil y sin embargo no figuran en ella.

El 21 de noviembre de 1853 se presentaba en el Congreso un proyecto de ley para ampliar en dos años el término dado por la ley de 19 de marzo de 1848 para reformar el Código penal, pero quedó pendiente su tramitación al suspenderse las sesiones en el mes de diciembre ${ }^{61}$.

Se encargó además el 14 de enero de 1854 a la Comisión la redacción de un proyecto de ley del Notariado ${ }^{62}$, y el 10 de mayo de 1854 el Ministro de Gracia y Justicia Jacinto Félix Doménech, del gobierno del Conde de San Luís, ordenó a la Comisión preparar un Código de instrucción civil ${ }^{63}$ abandonando esta todos sus otros trabajos.

El último de los trabajos de la Comisión se publicó a primeros de junio en la Gaceta: el Proyecto de ley constitutiva de los juzgados y Tribunales del fuero común, aprobado por secciones reunidas de procedimiento civil y criminal de la Comisión de Códigos ${ }^{64}$, para ser suprimida poco después ${ }^{65}$.

\section{I.4. Supresión}

La Vicalvarada de 1854 y la llegada de un gobierno progresista dirigido por Joaquín Fernández Alvárez Espartero, pone fin a esta segunda

${ }^{61}$ Lasso Gaite, Codificación penal..., I, pág. 384.

62 Antequera, La codificación moderna..., cit., pág. 77.

${ }^{63}$ Real Orden de 10 de mayo de 1854 mandando que la comisión de códigos proceda á redactar y discutir un código completo de instrucción civil (Gaceta de Madrid de 12/5/1854, n. $\left.{ }^{\circ} 497\right)$.

${ }^{64}$ Gaceta de Madrid de 01/06/1854, n. ${ }^{\circ} 517 ; 02 / 06 / 1854$, n. ${ }^{\circ} 518 ; 03 / 06 / 1854$, n. ${ }^{\circ} 519$; 04/06/1854, n. ${ }^{\circ} 520 ; 05 / 06 / 1854$, n. ${ }^{\circ} 521 ; 06 / 06 / 1854$, n. ${ }^{\circ} 522 ; 07 / 06 / 1854$, n. ${ }^{\circ} 523$; 08/06/1854, n. ${ }^{\circ} 524 ; 09 / 06 / 1854$, n. ${ }^{\circ} 525 ; 10 / 06 / 1854$, n. ${ }^{\circ} 526 ; 11 / 06 / 1854$ n. ${ }^{\circ} 527$.

${ }^{65}$ AnTeQuera, La codificación moderna..., cit., págs. 74-75. 
Comisión de Códigos de nuestra historia constitucional, mediante el siguiente decreto del Ministro de Gracia y Justicia José Alonso ${ }^{66}$ :

«Hallándose concluidos los principales trabajos que V. M. tuvo á bien confiar a la ilustración y celo de la Comisión de Códigos creada por Real decreto de 11 de septiembre de 1846, y encomendados los demás a una especial, se está en el caso de que aquella cese en sus funciones. En tal concepto el Ministro que suscribe, de acuerdo con el Consejo de Ministros somete a la aprobación de V. M. el siguiente proyecto de decreto. Madrid 18 de agosto de 1854.

\section{SEÑORA}

En atención a lo que me ha expuesto el Ministro de Gracia y Justicia, de acuerdo con el Consejo de Ministros vengo en decretar lo siguiente:

Artículo primero: Queda suprimida la Comisión de Códigos creada por mi Real decreto de 11 de septiembre de mil ochocientos cuarenta y seis.

Artículo segundo. Todos los trabajos, papeles y efectos de la Comisión se entregarán a la persona que se autorizará al efecto.

Artículo tercero: Los Magistrados pertenecientes á diferentes Tribunales que eran individuos de esta Comisión, pasaran desde luego a servir sus respectivas plazas. Dado en Palacio a dieciocho de agosto de mil ochocientos cincuenta y cuatro" ${ }^{67}$.

El decreto se comunicaba al día siguiente al Presidente de la Comisión de Códigos indicándole que los papeles debían ser entregados a Juan Gualberto López de Ceraín, oficial de la Secretaría del Ministerio, ordenando García Goyena al secretario de la Comisión su pronto cumplimiento ${ }^{68}$.

\section{I.5. La Comisión Especial de procedimiento civil de 1854}

El 14 de enero de 1854 se había creado una Comisión especial encargada de proponer las reformas pertinentes en la Instrucción de procedimiento civil de 30 de septiembre de 1853, del Marqués de Gerona.

José de Castro Orozco, marqués de Gerona, llegó al Ministerio de Gracia y Justicia en el gobierno del conservador conde de San Luis, y presentó en la Gaceta a los pocos días de su nombramien-

${ }^{66}$ ACGC, leg. 1, carpeta 11, doc. 1.

${ }^{67}$ Gaceta de Madrid de 20/8/1854, n. ${ }^{\circ} 596$.

${ }^{68}$ ACGC, leg. 1, carpeta 11, docs. 2 y 2 bis. 
to, la mencionada Instrucción cuya vigencia se extendió tan sólo a 1853. De dudosa autoría, aunque los estudiosos apuntan al propio Ministro quien la redactaría basándose en su propia experiencia, no fue redactada ni informada por la anterior Comisión de Códigos ${ }^{69}$, lo que contribuyó a acrecentar el que tras el cambio político fuese cuestionada, aunque la problemática fue patente desde el momento de su publicación debido a lo incisivo de su exposición de motivos que provocó numerosos malestares entre el colectivo judicial y en particular en el Colegio de Abogados de Madrid. Lo cierto es que, pese a que mediante una Real Orden de 19 de diciembre de 1853 se solicitó un informe de las Audiencias, Juzgados Decanos y Colegios de Abogados sobre la puesta en marcha de la Instrucción y ser el resultado de los mismos fundamentalmente positivo para la propia norma, existió una amplia predisposición en su contra, de ahí que fuese derogada por Real Decreto de 18 de agosto de $1854^{70}$.

En la Comisión convocada al efecto mediante una real orden dictada por el mismo Castro Orozco dos días antes de dimitir, jugó un papel especial Pedro Gómez de la Serna, que fue uno de los que firmantes de los escritos de protesta enviados por el Colegio de Madrid $^{71}$, y a la supresión de la misma se incorporó a la comisión encargada de la formación de los tribunales y del Código de procedimientos de $1854^{72}$. El resto de los miembros fueron Francisco Olavarrieta -Presidente del Tribunal Supremo- que la presidía, José María Huet, Juan María Biec -ambos Magistrados del Supremo-, Manuel Cortina -Decano del Colegio de Abogados de Madrid-, Manuel Ortiz de Zúñiga, Ramón Pasarón y Lastra, Francisco de Cárdenas y Domingo Rivera Vázquez ${ }^{73}$. Estos son todos los datos que poseemos de esta Comisión, que al parecer el gobierno pronto se convenció de la conveniencia de hacer un proyecto nuevo, tal y como ocurrió con posterioridad, reforzado por la orden de Jacinto Félix de Doménech, sustituto de Castro Orozco en el Ministerio, dirigida a la Comisión de ocuparse de este tema. La comisión es suprimida por Real Orden de 18 de septiembre de 1854 .

${ }^{69}$ LASso, Crónica.... cit., pág. 2, págs. 44-45. Acerca de la autoría véase además Prieto CASTRo, L., "La Instrucción del Marqués de Gerona "para arreglar el procedimiento de los negocios civiles con respecto a la jurisdicción ordinaria" », Revista General de Legislación y Jurisprudencia, 193 (1953), págs. 114-133.

${ }^{70}$ Gaceta de Madrid de 20/8/1854, n. ${ }^{\circ} 596$.

${ }^{71}$ Crónica de la codificación española. Vol. 2, Procedimiento civil, [Madrid], Ministerio de Justicia, Comisión General de Codificación, 1970, pág. 46.

${ }^{72}$ Lasso GaITe, Codificación penal..., cit. I, pág. 377.

73 Procedimiento civil, cit., pág. 55. 


\section{LA CODIFICACIÓN EN EL GOBIERNO PROGRESISTA (1854-1856)}

Comisión encargada de la formación de la ley en la organización de los tribunales y del Código de procedimientos fue el nombre de la Comisión de 1854 nombrada durante el Bienio Progresista de Baldomero Espartero.

Tras la supresión de la Comisión de 1846, el 11 de septiembre de 1854 una nueva Comisión era nombrada con el encargo específico de ocuparse de la organización judicial y la ley de Enjuiciamiento civil -cogiendo por ello ese nombre, aunque con el tiempo pasaría a ocuparte de la codificación con carácter general en todos los sectores necesarios-, tras haber derogado el Ministro José Alonso la Instrucción del Marqués de Gerona de 1853.

Son nombrados miembros de la comisión tan sólo tres personas: Pedro Gómez de la Serna, Luis Rodríguez Camaleño y Juan Manuel González Acevedo, incorporándose el 8 de octubre Manuel Cortina en calidad de presidente de la misma ${ }^{74}$. Esta Comisión formó las bases del Enjuiciamiento civil, que se sometieron a las Cortes y fueron aprobadas por la ley de autorización de 13 de mayo de 1855 y que desembocarían en la Ley de Enjuiciamiento civil de 5 de octubre de $1855^{75}$. Lamentablemente carecemos de actas de esta Comisión, por lo que no se puede dar cuenta de los trabajos realizados por la misma.

Una Real orden disponía que por la comisión de Códigos se redactase un proyecto de ley que diera pronto remedio á los graves inconvenientes ocasionados por las disposiciones contenidas en la regla 35 de la ley provisional para la aplicación del Código penal, y el decreto de 30 de Septiembre de 1853 sobre los casos en que debe ó no acordarse y ser efectiva la prisión de los pro$\operatorname{cesados}^{76}$, mientras que se reformaba el Código penal y las leyes que lo acompañaban. Se trataba de una comisión especial, que en realidad era una sección dentro de la Comisión, como podemos observar más adelante, nombrada el 25 de octubre de 1854 para el examen de las observaciones y contestaciones sobre Código $\operatorname{penal}^{77}$.

${ }^{74}$ ACGC, leg. 2, carpeta 1, doc. 2; ANTEQUERA, La codificación moderna..., cit., pág. 75.

${ }^{75}$ Lasso, Crónica..., cit., pág. 2, pág. 58.

${ }^{76}$ Gaceta de Madrid de 11/10/1855, n. ${ }^{\circ} 1011$.

${ }^{77}$ ACGC, Código penal, leg. 19, carpeta 1. 
Una petición de aumento en el número de vocales por parte de su Presidente motiva que el 8 de diciembre de 1854 Manuel Alonso Martínez sea nombrado Secretario de la Comisión de Códigos y se incorporen como vocales Manuel Pérez Hernández ${ }^{78}$ y el abogado del Colegio de Madrid José Ibarra ${ }^{79}$. El 21 de mayo de 1855 se incorporaba el Diputado Cirilo Álvarez ${ }^{80}$ y el 13 de julio de 1855 lo hacía el Fiscal del Tribunal Correccional de Madrid, José María Cáceres ${ }^{81}$. Poco después se nombraba miembros de la Comisión a Vicente Sebastián García, juez de primera Instancia ${ }^{82}$, y a Marcelino Trabadillo, relator de la Audiencia de Madrid ${ }^{83}$.

La Comisión recibió el encargo específico de revisar el proyecto de Código civil ${ }^{84}$, mediante el Decreto de 21 de febrero de 1855 del Ministro Joaquín Aguirre ${ }^{85}$, del segundo gobierno progresista de Espartero, y el aumento de tareas supuso la incorporación paulatina de vocales: Manuel de Seijas Lozano ${ }^{86}$, José de Galves Cañero -Fiscal del Tribunal de Guerra y Marina y diputado a Cortes-, los también diputados a Cortes Ruperto Navarro Zamorano y Nicolás María del Rivero ${ }^{87}$, y los catedráticos de la Universidad Central Pedro Sabau y Nicolás Núñez Arenas que se incorporaron el 21 de febrero de $1855^{88}$. Para ello se le dará traslado de los documentos existentes al tiempo de la desaparición de la sección del Código civil.

${ }^{78}$ Conservamos el escrito de aceptación de Pérez Hernández de fecha 10 de diciembre de 1854 (ACGC, leg, 2, carpeta 1, dic. 11), aunque el nombramiento consta en la carpeta de Alonso Martínez.

${ }^{79}$ ACGC, leg. 2, carpeta 1, doc. 40. Antequera da cuenta del nombramiento de Alonso Martínez, pero consigna a un tal Manuel Ibarra creemos que por error (ANTEQUERA, La codificación moderna..., cit., pág. 76). Ibarra solicitó el relevo y que el nombramiento se dejase sin efecto alegando la falta de conocimientos necesarios para el desempeño de la labor encomendada (ACGC, leg. 2, carpeta 1, doc. 41).

${ }^{80}$ ACGC, leg. 2, carpeta 1, doc. 8.

${ }^{81}$ ACGC, leg. 2, carpeta 1, doc. 45; ANTEQUeRA, La codificación moderna..., cit., pág. 78.

${ }^{82}$ Vicente Sebastián García fue nombrado el 9 de diciembre de 1954

${ }^{83}$ Que se incorpora el 31 de diciembre de 1954 (ACGC, leg. 2, carpeta 1, doc. 43).

${ }^{84}$ Martínez Alcubilla considera que el encargo de revisión de proyecto de Código civil se dio a la Comisión Especial, y también los de formulación del proyecto de ley de hipotecas y la reforma del Código penal, siendo suprimida el 1 de octubre de 1856 (Martínez Alcubilla, Diccionario de la Administración Española, cit., pág. 662).

${ }^{85}$ Lasso Gaite, Codificación civil..., cit., I, pág. 291.

${ }^{86}$ Quien renuncia el 3 de agosto de 1855 debido a su precario estado de salud (ACGC, leg. 2, carpeta 1, doc. 5).

${ }^{87}$ Tenemos constancia de la aceptación del cargo de Nicolás María Rivero el 26 de febrero de 1855 (ACGC, leg. 2, carpeta 1, doc. 44).

${ }^{88}$ ACGC, leg. 1, carpeta 12, docs. 1 y 2 . Antequera dice la incorporación se realizó el 21 de julio (ANTEQUERA, La codificación moderna..., cit., pág. 78), pero ello no concuerda con la documentación existente en la Comisión. 
Y además el 8 de agosto de 1855 se le encargaba priorizar la formación de una Ley Hipotecaria, cuyas bases se remitieron ${ }^{89}$, de ahí que se incorporen nuevos vocales como lo hizo el 14 de agosto lo hizo Vicente Hernández de la Rúa ${ }^{90}$. Junto a ello, una vez que se analizaron los informes enviados por las Audiencias y Colegios de Abogados sobre el Código penal, el proyecto de reforma que realizaron los Magistrados encargados del mismo se pasó a la Comisión para su estudio y aprobación a la mayor brevedad. También se encargó a la Comisión, el 15 de agosto de 1855, el análisis de un proyecto de reforma del Código penal presentado por Calderón Collantes ${ }^{91}$. Y por último el Ministro Manuel de la Fuente Andrés, del tercer gobierno progresista de Espartero, encargó a la Comisión mediante la real orden de 5 de octubre de 1855 la elaboración de un proyecto de ley que contemplase los casos en que debía o no acordarse la prisión de los procesados ${ }^{92}$.

Fue de tal magnitud la labor de esta Comisión, que la Reina dio muestras de agradecimiento hacia sus miembros el 31 de octubre de 1855 constando una relación de los mismos, que nos sirve para comprobar cómo estaba estructurada la Comisión ${ }^{93}$ :

${ }^{89}$ Según estas bases, se debía partir del principio de publicidad de las hipotecas, no admitir las hipotecas generales, establecer las formalidades para la traslación de la propiedad y estudiar las hipotecas legales (ANTEQUERA, La codificación moderna...., cit., pág. 77).

${ }_{90}$ Vicente Hernández de la Rúa era Teniente Fiscal del Tribunal Supremo y diputado a Cortes (ACGC, leg. 2, carpeta 1, dic. 46). La comunicación del nombramiento lleva fecha de 11 de agosto de 1855, por lo que la fecha consignada por Antequera puede ser la de su verdadera incorporación (Ibid., pág. 78). Vid. Procedimiento civil..., cit., pág. 59 .

${ }^{91}$ LASso GAITE, Codificación penal..., cit., I, pág. 386.

${ }^{92}$ Ibid., I, pág. 385.

93 «Enterada la Reina q.D.g. con especial satisfacción de las arduas tareas y del constante desvelo con que la Comisión que V. E. tan dignamente preside, se ha dedicado a la formación de la ley de enjuiciamiento civil, conforme a las bases fijadas por la ley de autorización de 13 de mayo del corriente año, a cuyo importante trabajo se ha servido dar su Real aprobación por decreto de 5 del actual; y deseando S. M. premiar, como es justo, servicios que han de formar época por su resultado en los fastos legislativos y judiciales del pais, al mismo tiempo que galardonar, en cuanto es posible, tan distinguido celo, tan acreditada ilustración y tan acertado patriotismo, se ha dignado mandar que manifiesta a V. E. como de su real orden tengo la satisfacción de egecutarlo, para su conocimiento y el de los dignos miembros de la Comisión, D. Pedro Gómez de la Serna, D. Luis Rodríguez Camaleño, D. Juan Manuel González Acevedo, D. Manuel Pérez Hernández, D. Manuel Alonso Martínez, D. Vicente Sebastián García, D. Marcelino Trabadillo, D. José de Galvez Cañero, D. Ruperto Navarro Zamorano, D. Nicolás María del Rivero, D. Pedro Sabau, D. Ysaac Nuñez Arenas, D. Cirilo Alvarez, D. José María Cáceres, D. Vicente Hernández de la Rúa, que S. M. está en sumo grado complacida del espresado tra- 
1. Comisión general de Códigos.

Presidente: Manuel Cortina.

Vocales: $\quad$ Pedro Gómez de la Serna.

Manuel Pérez Hernández.

Luis Rodríguez Camaleño.

Marcelino Trabadillo.

Juan Manuel González Acevedo.

Pedro Sabau.

Vicente Sebastián García.

José de Gálvez Cañero.

Isaac Núñez Arenas.

Cirilo Álvarez.

Nicolás María Rivero.

Vicente Hernández de la Rua.

Tomás Vizmanos.

Manuel de la Fuente Andrés ${ }^{94}$.

Secretario: José María Cáceres.

Manuel Alonso Martínez.

2. Sección encargada del Proyecto de organización de Tribunales.

Presidente: Luis Camaleño.

Vicente Sebastián García.

José Gálvez Cañero.

Isaac Núñez Arenas.

3. Sección encargada de la revisión del Proyecto de Código civil.

Presidente: Pedro Sabau.

Manuel Pérez Hernández.

Nicolás Rivero.

\begin{abstract}
bajo, y que da sus reales gracias a V. E. y a los referidos vocales; siendo su voluntad que tan distinguido merecimiento y el que siguen contrayendo en las demas obras difíciles que forman parte de su elevada y honrosa mision, se tengan presentes en su carrera para remunerarlos debidamente y en ocasión oportuna: y que esta junta manifiestacion se haga estensiva al presidente y vocales que fueron de la primitiva comisión encargada de proponer las reformas que, en su concepto, fuese conveniente hacer en los artículos de la Real Instrucción del procedimiento de 30 de septiembre de 1853 D. Francisco Olavarrieta, Presidente que era del Supremo Tribunal de Justicia, Don José María Huet, D. Juan María Brie, Don Pedro Gómez de la Serna, D. Manuel Ortiz de Zúñiga, D. Ramon Pasaron y Lastra, D. Juan de Cárdenas y D. Domingo Ribera y Vazquez, por el celo, laboriosidad é inteligencia con que se dedicaron a preparar los elementos de la referida ley en union con V. E. Lo que de Real Orden traslado a V. e. para su inteligencia y satisfacción» (ACGC, leg. 1, carpeta 12, doc. 3; Gaceta de Madrid de 3/11/1855, n. ${ }^{\circ} 1034$ ).

${ }^{94}$ Este ex ministro de Gracia y Justicia fue nombrado el 6 de febrero de 1658 (ACGC, leg. 2, carpeta 1, doc. 47).
\end{abstract}


Manuel Alonso Martínez.

Cirilo Álvarez.

4. Sección encargada de un Proyecto de ley sobre Procedimientos criminales.

Presidente: Juan Manuel González Acevedo.

Marcelino Trabadillo.

Manuel Pérez Hernández.

Manuel Alonso Martínez.

5. Sección encargada del Proyecto de reforma del Código penal.

Presidente: Pedro Gómez de la Serna.

Vicente Hernández de la Rúa.

Tomás Vizmanos.

José Cáceres.

6. Sección encargada del Proyecto de ley de Hipotecas.

Presidente: Manuel Cortina.

Juan Manuel González Acevedo.

7. Sección encargada del Proyecto de ley de prisiones.

Presidente: Pedro Gómez de la Serna.

Marcelino Trabadillo.

Vicente Sebastián García.

Vicente Hernández de la Rúa.

José Cáceres.

8. Sección encargada del informe sobre inamovilidad, etc.

Presidente: Manuel Alonso Martínez.

Cirilo Álvarez.

Tomás Vizmanos.

Las últimas incorporaciones se realizan en 1856: el 29 de abril de 1856 se incorporaba a la Comisión el Magistrado cesante de la Audiencia de Madrid, José de Olózaga ${ }^{95}$, el 6 de junio lo hacía Florencio Rodríguez Valdes, Presidente de Sala de la Audiencia de Albacete ${ }^{96}$ y por último, el 12 de julio, Sebastián Rodríguez Nandín, Magistrado cesante del Tribunal Supremo, y Santiago Aguiar y Mella, Subsecretario del Ministerio de Gracia y Justicia ${ }^{97}$.

${ }^{95}$ ACGC, leg. 2, carpeta 1, doc. 48.

${ }^{96}$ ACGC, leg. 2, carpeta 1, doc. 49.

${ }^{97}$ ACGC, leg. 2, carpeta 1, docs. 50 y 51. 
Un nuevo cambio político, el operado en el verano de 1856 supondrá un giro en la política codificadora. El gobierno de la Unión Liberal presidido por O’Donell, suprimirá está Comisión para convocar otra, la primera que lleva el apelativo de "codificación», que será presidida por Manuel Cortina, mediante el Decreto siguiente:

«Atendiendo a las razones que me ha expuesto el Ministerio de Gracia y Justicia, y de acuerdo con el Consejo de Ministros, vengo en decretar lo siguiente:

1. Se suprime la Comisión de códigos creada por mi Real Disposición de 11 de septiembre de 1854, ampliada por otras posteriores, quedando altamente satisfecha del celo e inteligencia con que sus individuos han correspondido á mi confianza, reservándome decretar las recompensas á que se hayan hecho acreedores, y utilizar oportunamente sus servicios.

2. ${ }^{\circ}$ Se crea una nueva Comisión de codificación compuesta de siete individuos y un Secretario sin voto, que será retribuido por el Ministerio de Gracia y Justicia con la asignación correspondiente.

3. La comisión, a la cual se pasarán los trabajos existentes, se ocupará con preferencia, y por un orden sucesivo, de los proyectos de ley sobre organización judicial, procedimiento criminal, reforma del Derecho penal vigente, y ultimamente del Código civil.

4. ${ }^{\circ}$ El Ministro de Gracia y Justicia queda encargado de la ejecucion del presente decreto. Dado en Palacio a 1. ${ }^{\circ}$ de octubre de 1856.Está rubricado de la Real Mano.-El Ministro de Gracia y Justicia Cirilo Alvarez» ${ }^{98}$.

\section{CONCLUSIONES}

Es preciso realizar una labor de reconstrucción institucional importante de la codificación en nuestro país. La obra de Jose M. ${ }^{a}$ de Antequera es un punto de partida importante pero incompleto respecto de la evolución de la codificación en España. Los magníficos estudios de Lasso Gaite y sus ayudantes sólo dan una visión sectorial de la codificación que es preciso unificar partiendo de la misma para ampliar los datos que faltan con la documentación existente en los archivos y la bibliografía de la época.

${ }^{98}$ Gaceta de Madrid de 2/10/1856, n. ${ }^{\circ}$ 1368. Un dato curioso es que según un documento sin fecha existente en el expediente de Cirilo Alvarez, la Comisión se suprimiría por el Real Decreto de 6 de septiembre de 1856 en que se crea la nueva Comisión codificadora, datos corroborados por una certificación expedida el 11 de septiembre de 1874 por el auxiliar de la Secretaría del Ministerio Joaquín Cabezas, en virtud de la documentación existente en el archivo (ACGC, leg. 2, carpeta 1, doc 8$)$. 
Durante el reinado de Isabel II, salvo el periodo conocido como Década moderada en la que fueron dos las comisiones convocadas (la de 1843 y la de 1846), por el efecto de la intervención y control directo de Juan Bravo Murillo, las reformas en las Comisiones se deben fundamentalmente a los cambios en la orientación ideológica del gobierno y a la fuerte politización de las Comisiones: durante el bienio progresista (1854-1856) se convocará una nueva Comisión y la Unión Liberal (1856-1868), propiciará una nueva comisión de la que no nos ocupamos en este trabajo. Esos cambios afectarán fundamentalmente a los sucesivos presidentes, aunque veremos que fundamentalmente existe un núcleo acreditado formado por inminentes juristas que asistirán casi invariablemente a las diferentes comisiones convocadas.

La comisión de Códigos de 1843 fue suprimida sin causa justificada, debido a las manipulaciones de Bravo Murillo.

Como ya he demostrado en múltiples ocasiones la denominación exacta de las comisiones que se encargaron de la primera codificación en España no es "Comisión General de codificación», ni tan siquiera "Comisión de Codificación», como hasta la actualidad se viene utilizando al utilizar la denominación por la finalidad que se le atribuía y tareas a las que se dirigían sino «Comisión de Códigos».

La primera Comisión de Codificación existente en España es la de 1856, no pudiendo utilizarse con anterioridad ese nombre pues expresamente e incluso en los membretes de la documentación figura la denominación "Comisión de Códigos». No obstante la Comisión de 1856 en modo alguno puede ser llamada "Comisión General de Codificación». La Comisión General de Codificación surge tiempo después de las que hemos analizando hasta este momento. 